\title{
The Role of Pulmonary Artery Wedge Pressure on the Incidence of Atrial Fibrillation and Atrial Tachycardias in Patients With Isolated Pre-capillary Pulmonary Hypertension
}

\author{
Milan DUSIK ${ }^{1}$, Zdenka FINGROVA ${ }^{1}$, David AMBROZ ${ }^{1}$, Pavel JANSA ${ }^{1}$, Ales LINHART ${ }^{1}$, \\ Stepan HAVRANEK ${ }^{1}$ \\ ${ }^{1} 2^{\text {nd }}$ Department of Medicine, Department of Cardiovascular Medicine, General University Hospital \\ in Prague, $1^{\text {st }}$ Faculty of Medicine, Charles University in Prague, Prague, Czech Republic
}

Received April 17, 2021

Accepted September 13, 2021

Epub Ahead of Print October 30, 2021

\section{Summary}

Atrial fibrillation and atrial tachycardias (AF/AT) have been reported as a common condition in patients with pulmonary hypertension (PH). As yet, limited data exists about the significance of the borderline post-capillary pressure component on the occurrence of AF / AT in patients with isolated pre-capillary $\mathrm{PH}$. We retrospectively studied the prevalence of AF / AT in 333 patients (mean age $61 \pm 15$ years, $44 \%$ males) with pre-capillary idiopathic / familiar pulmonary arterial hypertension, and inoperable chronic thromboembolic pulmonary hypertension. The prevalence of AF / AT was analyzed in different categories of pulmonary artery wedge pressure (PAWP). In the study population overall, the mean PAWP was $10.5 \pm 3 \mathrm{mmHg}$, median of $11 \mathrm{mmHg}$, range 2-15 $\mathrm{mmHg}$. AF / AT was diagnosed in 79 patients (24\%). The proportion of AF / AT among patients with PAWP below the median $(\leq 11 \mathrm{mmHg}$ ) was lower than in subjects with PAWP between 12 and $15 \mathrm{mmHg}, 30$ (16 \%) vs. 46 (35\%), $p=0.0001$. Compared to the patients with PAWP $\leq 11 \mathrm{mmHg}$, subjects with PAWP between 12 and $15 \mathrm{mmHg}$ were older ( $65 \pm 13$ years vs. $58 \pm 16)$, with more prevalent arterial hypertension [100 (70 \%) vs. $106(55 \%)]$ and diabetes mellitus [50 (35\%) vs. $48(25 \%)$, showed larger size of the left atrium ( $42 \pm 7$ vs. $40 \pm 6 \mathrm{~mm}$ ), and higher values of right atrium pressure $(12 \pm 5$ vs. $8 \pm 5 \mathrm{mmHg}), \mathrm{p}<0.05$ in all comparisons. The prevalence of AF / AT in the group studied increased with the growing post-capillary component.

\section{Key words}

Pulmonary hypertension • Atrial fibrillation • Atrial tachycardia • Atrial flutter $\bullet$ Pulmonary artery wedge pressure

\section{Corresponding author}

Stepan Havranek, U Nemocnice 2, 12808 Prague, Czech Republic. E-mail: stepan.havranek@lf1.cuni.cz

\section{Introduction}

Pulmonary hypertension (PH) is a pathophysiological disorder, which is defined by the elevation of pulmonary artery mean pressure (PAMP) to above $25 \mathrm{mmHg}$. Pulmonary artery wedge pressure (PAWP) is crucial in distinguishing between pre-capillary (PAWP $\leq 15 \mathrm{mmHg}$ ) and post-capillary $\mathrm{PH}$ (PAWP $>15 \mathrm{mmHg}$ ). Based on the hemodynamic characteristics, pathological findings, and a similar clinical presentation, $\mathrm{PH}$ can be categorized into 5 main groups (Galie et al. 2016, Simonneau et al. 2004). Despite the recent developments of various treatment strategies, which have improved the hemodynamics, exercise capacity, and the quality of life in patients with $\mathrm{PH}$, the prognosis of $\mathrm{PH}$ is generally inauspicious. (Galie et al. 2016)

Supraventricular tachycardias (SVTs), including atrial fibrillation and atrial tachycardias (AF / AT), have been reported as a common condition in patients with $\mathrm{PH}$ of different aetiologies. The range of cumulative incidence of SVTs varies between 10-36 \%, including all types of pulmonary arterial hypertension (PAH) (Fingrova et al. 2021, Olsson et al. 2013, Rottlaender et al. 2012, Smith et al. 2018, Wen et al. 2014), Eisenmenger's syndrome (Cannillo et al. 2015), or inoperable chronic thromboembolic $\mathrm{PH} \quad(\mathrm{CTEPH})$ 
(Rottlaender et al. 2012, Smith et al. 2018, Tongers et al. 2007). A high prevalence of AF / AT was also identified in CTEPH patients treated with pulmonary endarterectomy, with a high number of newly diagnosed AF / AT during long-term follow-up after surgery (Fingrova et al. 2019).

SVTs in patients with $\mathrm{PH}$ frequently lead to clinical deterioration (Fingrova et al. 2021, Olsson et al. 2013, Rottlaender et al. 2012, Smith et al. 2018, Tongers et al. 2007, Wen et al. 2014), and arrhythmia development has also been investigated as a predictor of mortality (Cannillo et al. 2015, Olsson et al. 2013, Smith et al. 2018, Wen et al. 2014). Sinus rhythm (SR) restoration appears to improve the clinical outcome at least in patients with idiopathic PAH (IPAH) and inoperable CTEPH (Olsson et al. 2013, Wen et al. 2014).

It has been also shown that the prevalence of particular types of SVTs can differ according to the aetiology of $\mathrm{PH}$. A high number of AF was reported in patients with post-capillary $\mathrm{PH}$, leading to an overall higher arrhythmia prevalence in this group (Galie et al. 2004, Galie et al. 2009).

However, only a little is known about the significance of the borderline post-capillary pressure component on the occurrence of $\mathrm{AF} / \mathrm{AT}$ in patients with pre-capillary $\mathrm{PH}$. In a former work from our centre, it has been demonstrated that even in those patients left-sided substrate could play an important role in the arrhythmogenesis of complex atrial arrhythmia (Fingrova et al. 2019).

Therefore, we analysed data from a large singlecentre database with the aim of identifying the impact of concrete PAWP values on AF / AT (common atrial flutter including) prevalence. The secondary objective was to describe the differences between patients with early and late onset of arrhythmia in terms of the predisposing factors and hemodynamics.

\section{Methods}

We performed a retrospective analysis of a dedicated registry of consecutive patients who were diagnosed and treated for idiopathic or familiar $\mathrm{PAH}$ (IPAH / FPAH) or inoperable CTEPH at a single centre between 2003 and 2017. The final follow-up was set for December 2018. The study was performed according to the principles of good clinical practice and in compliance with the Declaration of Helsinki. The whole study was approved by the local Ethics committee (Ethics Committee in General University Hospital in Prague,
No. 1121/16-S-IV). All patients gave written informed consent agreeing to data collection and analysis for scientific purposes.

Detailed protocol of the study has been described previously (Fingrova et al. 2019). In brief, all involved patients underwent a routine baseline work-up, according to contemporary standards (Galie et al. 2004, Galie et al. 2009, Galie et al. 2016), including all indicated non-invasive and invasive methods, and right heart catheterization to confirm and classify $\mathrm{PH}$. The diagnosis of PH required a confirmation of the PAMP $\geq 25 \mathrm{mmHg}$ by the baseline right heart catheterization.

Patients with combined post- and pre-capillary $\mathrm{PH}$ [defined as PAMP $\geq 25 \mathrm{mmHg}$ and simultaneous elevation of PAWP $>15 \mathrm{mmHg}$ and pulmonary vascular resistance $(\mathrm{PVR})>3$ Wood Units (WU)] or with isolated post-capillary $\mathrm{PH}$ (defined as PAMP $\geq 25 \mathrm{~mm} \mathrm{Hg}$ and PAWP $>15 \mathrm{~mm} \mathrm{Hg}$, but having a PVR $\leq 3 \mathrm{WU}$ ) were excluded from the study (Galie et al. 2016).

All patients were evaluated regularly at 1 to 6 monthly intervals, or whenever clinically indicated. For further evaluation, the time of the PH diagnosis was set as the beginning of the study. Routine examinations and standard 12-lead ECGs were obtained as part of the regular follow-up program. A 24-hour, 48-hour or longer ECG monitoring was performed when indicated by a clinician based mainly on paroxysmal arrhythmia suspicion. The period of monitoring was dictated by the clinical situation. A prevalent AF or AT was defined as evidence of the presence of a documented arrhythmia on the standard 12-lead ECGs and / or ECG monitors in a patient's personal history, or at the time of diagnosis or during a follow-up. The diagnosis of an AF / AT was confirmed by an experienced cardiologist in each case. For the purpose of the study, common atrial flutter was included into the AT group. All types of AF (paroxysmal, persistent, permanent) were included.

\section{Statistical analysis}

The continuous variables were expressed as means with standard deviations. After testing for normality (Shapiro-Wilk's test) the data was compared using the 2-tailed t-test for independent samples or advanced ANOVA tests to compare more than two means. The categorical variables were expressed as percentages and compared by the $\chi^{2-\text { test }}$ or the Kruskal-Wallis test when appropriate. A P-value of $<0.05$ was considered as significant. All analyses were performed using the STATISTICA vers.12 software (Statsoft, Inc., Tulsa, USA). 
Table 1. Baseline clinical and demographical characteristics.

\begin{tabular}{|c|c|c|c|c|}
\hline & $\begin{array}{c}\text { Total } \\
\mathbf{n}=\mathbf{3 3 3}\end{array}$ & $\begin{array}{c}\text { ARRHYTHMIA } \\
\begin{array}{c}\text { NO } \\
\mathbf{n}=\mathbf{2 5 4}\end{array}\end{array}$ & $\begin{array}{c}\text { ARRHYTHMIA } \\
\text { YES } \\
\mathbf{n}=79\end{array}$ & p value \\
\hline Age at diagnosis of $P H$ (years) & $61 \pm 15$ & $58 \pm 16$ & $69 \pm 9$ & $<0.0001$ \\
\hline Male gender & $145(44 \%)$ & $109(43 \%)$ & $36(46 \%)$ & NS \\
\hline Arterial hypertension & $206(62 \%)$ & $140(55 \%)$ & $66(84 \%)$ & 0.0001 \\
\hline Diabetes mellitus & $98(29 \%)$ & $60(24 \%)$ & $38(48 \%)$ & 0.0001 \\
\hline$I P A H / F P A H$ & $214(64 \%)$ & $165(65 \%)$ & $49(62 \%)$ & NS \\
\hline Inoperable CTEPH & $119(36 \%)$ & $89(35 \%)$ & $30(38 \%)$ & NS \\
\hline Specific therapy & $235(71 \%)$ & $179(70 \%)$ & $56(71 \%)$ & NS \\
\hline \multicolumn{5}{|l|}{ NYHA (class) } \\
\hline$I$ & $4(1 \%)$ & $3(1 \%)$ & $1(1 \%)$ & NS \\
\hline II & $62(19 \%)$ & $51(20 \%)$ & $11(14 \%)$ & NS \\
\hline III & $219(66 \%)$ & $162(64 \%)$ & $57(72 \%)$ & NS \\
\hline$I V$ & $48(14 \%)$ & $38(15 \%)$ & $10(13 \%)$ & NS \\
\hline $6 M W T$ (meters) & $326 \pm 129$ & $334 \pm 131$ & $298 \pm 120$ & 0.036 \\
\hline$L A$ in $P L A X(m m)$ & $41 \pm 7$ & $39 \pm 6$ & $45 \pm 7$ & $<0.0001$ \\
\hline$L V E F(\%)$ & $63 \pm 8$ & $63 \pm 8$ & $62 \pm 8$ & NS \\
\hline LVEDD in PLAX (mm) & $45 \pm 8$ & $44 \pm 10$ & $48 \pm 7$ & 0.001 \\
\hline$R A$ in $A 4 C(\mathrm{~mm})$ & $48 \pm 10$ & $47 \pm 10$ & $49 \pm 11$ & NS \\
\hline$R V$ in $A 4 C(\mathrm{~mm})$ & $45 \pm 10$ & $45 \pm 10$ & $44 \pm 9$ & NS \\
\hline TAPSE $(\mathrm{mm})$ & $18 \pm 5$ & $19 \pm 5$ & $17 \pm 5$ & NS \\
\hline$P A M P(m m H g)$ & $47 \pm 13$ & $48 \pm 14$ & $45 \pm 12$ & NS \\
\hline$R A P(m m H g)$ & $10 \pm 5$ & $9 \pm 5$ & $11 \pm 5$ & 0.033 \\
\hline Follow-up duration (years) & $4.1 \pm 2.7$ & $4.1 \pm 2.8$ & $4.1 \pm 2.5$ & NS \\
\hline
\end{tabular}

Values are expressed as mean \pm SD or $n(\%)$. NS - non-significant; $\mathrm{PH}$ - pulmonary hypertension; IPAH / FPAH - idiopathic / familiar pulmonary arterial hypertension; CTEPH - chronic thromboembolic pulmonary hypertension; 6MWT - six minute walking test; LA - left atrium; LV - left ventricle; EF - ejection fraction; LVEDD - left ventricular end-diastolic diameter; RA - right atrium; RV - right ventricle; TAPSE - tricuspid annular plane systolic excursion; PAMP - pulmonary arterial mean pressure; RAP - right atrial pressure; PLAX parasternal long axis view; A4C - apical four chamber view.

\section{Results}

A total of 333 patients (mean age $61 \pm 15$ years, $44 \%$ males) were included in the analysis. AF / AT was diagnosed in 79 patients $(24 \%)$. The baseline clinical and demographical characteristics of the total population and subgroups are shown in Table 1. In summary, patients who developed arrhythmia were of a slightly higher age, had higher prevalence of arterial hypertension and diabetes mellitus, had a reduced 6MWT distance, higher left atrium (LA) diameter, slightly bigger end-diastolic left ventricular diameter, and a more elevated right atrial pressure (RAP).

In the overall study population, the mean PAWP was $10.5 \pm 3 \mathrm{mmHg}$, range $2-15 \mathrm{mmHg}$, mode of $11 \mathrm{mmHg}$, median of $11 \mathrm{mmHg}$, interquartile range
(IQR) of 8-13 mmHg. Patients with manifest AF / AT had higher values of PAWP than those subjects without arrhythmia $(12 \pm 3$ vs $10 \pm 3 \mathrm{mmHg}, \mathrm{p}=0.001)$. The proportion of patients with and without AF / AT in relation to their PAWP values is shown in the histogram in Figure 1.

The distribution of the prevalence of AF / AT in different intervals of PAWP is depicted in Figure 2. Those patients in the two lower PAWP groups $(\leq 11 \mathrm{mmHg})$ had significantly reduced occurrence of arrhythmia, then patients in the upper two subgroups (30 (16\%) vs. $46(35 \%), p=0.0001)$.

As shown in Table 2, patients with PAWP $\leq 11 \mathrm{mmHg}$ were younger, with less prevalent arterial hypertension and diabetes mellitus, a lower size of LA, and lower values of RAP than those with PAWP between 
12 and $15 \mathrm{mmHg}$.

Of all the patients with arrhythmia, 48 (61\%) had no history of AF / AT at the time of diagnosis of PH. When compared to patients with a history of arrhythmia prior to the diagnosis of $\mathrm{PH}$, those patients with arrhythmia manifestation during the follow-up were younger at the time of $\mathrm{PH}$ diagnosis $(64 \pm 10$ vs.

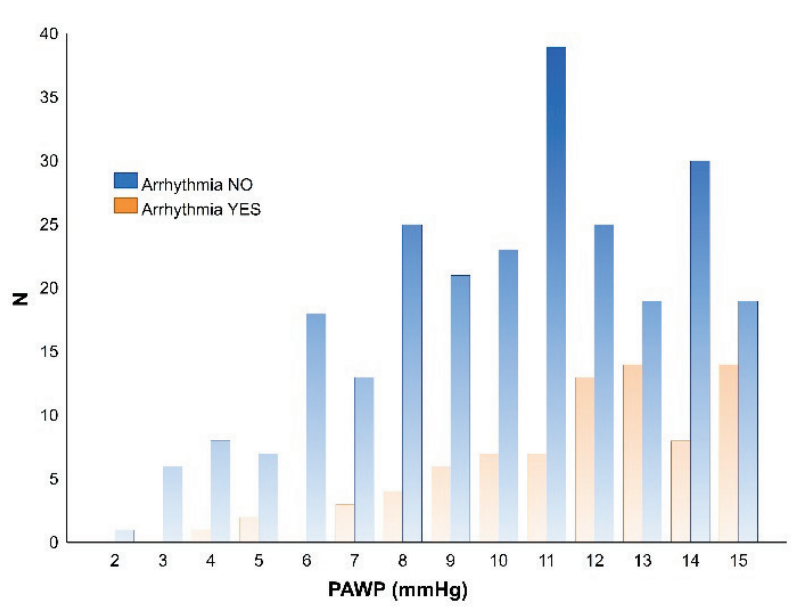

Fig. 1. Proportions of pulmonary artery wedge pressures in patients with and without atrial fibrillation or atrial tachycardia. PAWP - pulmonary artery wedge pressure.

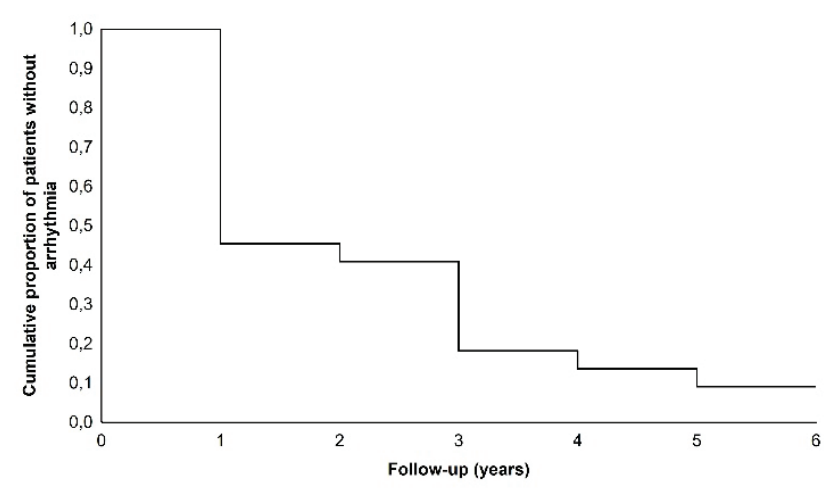

$\begin{array}{lcccccc}\text { Patients at risk: } & 231 & 183 & 127 & 85 & 42 & 9 \\ \text { Incidence of AF / AT: } 12(5 \%) & 1(0.5 \%) & 5(4 \%) & 1(1 \%) & 2(5 \%) & 1(11 \%)\end{array}$

Fig. 3. Annual incidence of arrhythmia during follow-up. AF / AT atrial fibrillation / atrial tachycardia.

\section{Discussion}

SVTs are usually reported as common comorbidities in patients with $\mathrm{PH}$, and the total prevalence of AF / AT was high in our registry as well (almost $24 \%$ ). The main finding of our study is that in patients with invasively confirmed isolated pre-capillary $\mathrm{PH}$ the prevalence of AF / AT is very likely increasing with the growing post-capillary component. The group of
$72 \pm 7$ years, $p=0.0004)$. There were no statistically significant differences in the remaining variables. The spectrum of arrhythmias is shown in Table 3.

When only the patients with arrhythmia onset after the diagnosis of $\mathrm{PH}$ are analysed, the annual incidence of AF / AT is between 0.5 and $11 \%$, as shown in Fig. 3.

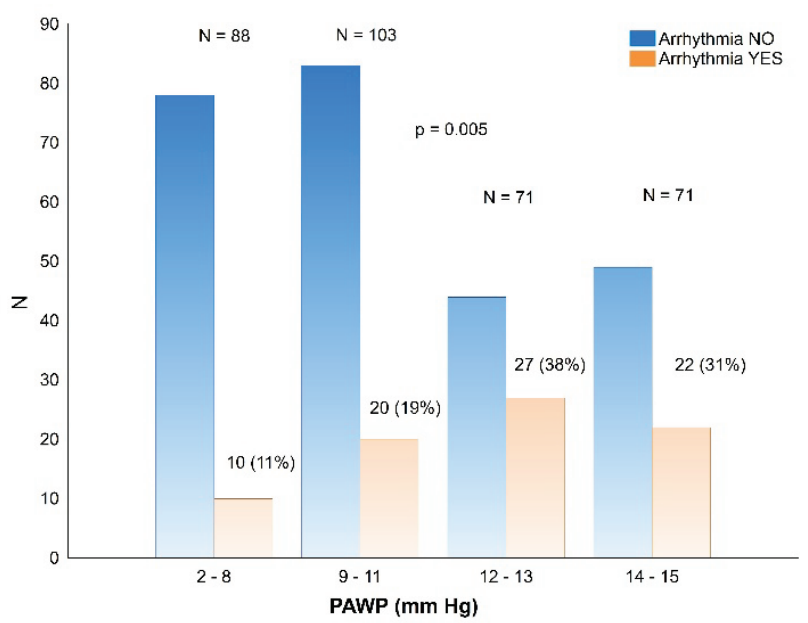

Fig. 2. Proportion of patients with and without atrial fibrillation or atrial tachycardia according to the values of pulmonary artery wedge pressure. PAWP - pulmonary artery wedge pressure.

patients with near to elevated PAWP (e.g. 11-15 mmHg) had a significantly higher occurrence of arrhythmia than patients with lower PAWP $(\leq 11 \mathrm{mmHg})$.

An exact arrhythmogenic substrate for complex atrial arrhythmias, including AF or AT in PH patients, remains unclear. There is emerging evidence indicating a significant role of right-sided substrate for complex atrial arrhythmia, based on the fact that $\mathrm{PH}$ leads to an increased afterload of the right ventricle (RV), resulting in $\mathrm{RV}$ hypertrophy and dilatation, as well as upstream enlargement of the right atrium (RA) (Pietra et al. 2004). Long-standing $\mathrm{PH}$ is frequently associated with decreased conduction and tissue voltage in some cases, with regions of "electrical silence" occurring in both the RA and RV (Medi et al. 2012). In addition, modulations of the autonomic system may trigger and perpetuate related arrhythmia (Folino et al. 2003, Schrier and Bansal 2008).

All patients in our study have been diagnosed as $\mathrm{PH}$. Therefore, the role of right-sided proarrhythmogenic substrate is probable, which is supported by supranormal dimensions of RA and RAP elevation that could be found in our cohort. These findings also give us evidence about severity of $\mathrm{PH}$ and for example RA enlargement was 
already proven as an independent predictor of adverse outcome in PH patients (Cioffi et al. 2007). But it is necessary to mention, that even in an isolated precapillary PH could also the left-sided substrate play a particular role in the arrhythmogenesis of complex atrial arrhythmia. (Fingrova et al. 2019).

However, when a post-capillary component is present, the mechanisms of arrhythmia have been suggested as being more similar to a proarrhythmogenic substrate in left heart disease (Rottlaender et al. 2012). Elevated PAWP and end-diastolic left ventricular pressure represent a well-known mechanism leading to LA structural remodelling with a proarrhythmogenic effect. Left atrial remodelling, particularly LA dilatation, is a well-documented risk factor for the development of AF (Ausma et al. 1997, Spach and Josephson 1994).

According to our data, left atrium dimensions are abnormal in patients with nearly elevated PAWP and significantly bigger compared to patients with lower
PAWP. By other words, there is a distinct echo finding of bi-atrial enlargement, that indicates possible combined left and right atrial substrate in this group of patients. We believe that the increased prevalence of $\mathrm{AF} / \mathrm{AT}$ in patients with higher values of PAWP is caused by simultaneous presence and additive effect of the LA substrate.

One factor which possibly explains the involvement of the left heart in the pathogenesis of $\mathrm{AF} /$ AT in PH patients may be due to the definition of pre-capillary $\mathrm{PH}$ itself. $\mathrm{PH}$ diagnosis is based uniquely on the resting invasive pulmonary pressure measurements. In addition, the PAWP limit is set relatively high above the limits of the presumed true physiological values. This may lead to a diagnosis of purely pre-capillary $\mathrm{PH}$ in a group of patients, in whom the $\mathrm{PH}$ is actually of the combined type (combined post-capillary and pre-capillary $\mathrm{PH}$ ). It has been repeatedly shown (Borlaug et al. 2010, D'Alto et al. 2017) that a fluid challenge or exercise can unmask the postcapillary component in a large number of patients.

Table 2. Clinical parameters in patients with low and higher pulmonary artery wedge pressure.

\begin{tabular}{|c|c|c|c|}
\hline Category $(P A W P)$ & $\begin{array}{c}\leq 11 \mathrm{mmHg} \\
\quad \mathrm{N}=191\end{array}$ & $\begin{array}{c}12-15 \mathrm{mmHg} \\
\mathrm{N}=142\end{array}$ & p value \\
\hline Age at diagnosis of $\mathrm{PH}$ (years) & $58 \pm 16$ & $65 \pm 13$ & 0.0002 \\
\hline Male gender & $85(45 \%)$ & $60(42 \%)$ & NS \\
\hline Art. hypertension & $106(55 \%)$ & $100(70 \%)$ & 0.005 \\
\hline Diabetes mellitus & $48(25 \%)$ & $50(35 \%)$ & 0.047 \\
\hline$I P A H / F P A H$ & $129(68 \%)$ & $85(60 \%)$ & NS \\
\hline СТEPH & $62(32 \%)$ & $57(40 \%)$ & NS \\
\hline Specific therapy & $136(71 \%)$ & $100(70 \%)$ & NS \\
\hline \multicolumn{4}{|l|}{ NYHA (class) } \\
\hline$I$ & $2(1 \%)$ & $2(1 \%)$ & NS \\
\hline II & $36(19 \%)$ & $26(18 \%)$ & NS \\
\hline III & $130(68 \%)$ & $89(63 \%)$ & NS \\
\hline$I V$ & $23(12 \%)$ & $25(18 \%)$ & NS \\
\hline $6 M W T$ (meters) & $329 \pm 129$ & $320 \pm 130$ & NS \\
\hline$L A$ in $P L A X(\mathrm{~mm})$ & $40 \pm 6$ & $42 \pm 7$ & 0.03 \\
\hline$L V E F(\%)$ & $63 \pm 8$ & $63 \pm 8$ & NS \\
\hline LVEDD in PLAX (mm) & $44 \pm 7$ & $46 \pm 8$ & NS \\
\hline$R A$ in $A 4 C(\mathrm{~mm})$ & $48 \pm 10$ & $47 \pm 10$ & NS \\
\hline$R V$ in $A 4 C(\mathrm{~mm})$ & $46 \pm 9$ & $43 \pm 10$ & NS \\
\hline TAPSE (mm) & $18 \pm 5$ & $19 \pm 6$ & NS \\
\hline$P A M P(m m H g)$ & $47 \pm 13$ & $48 \pm 13$ & NS \\
\hline$R A P(m m H g)$ & $8 \pm 5$ & $12 \pm 5$ & 0.0001 \\
\hline Follow-up duration (years) & $4.3 \pm 2.9$ & $3.9 \pm 2.4$ & NS \\
\hline
\end{tabular}

Values are expressed as mean \pm SD or $n(\%)$. NS - non-significant; PAWP - pulmonary artery wedge pressure; PH - pulmonary hypertension; IPAH / FPAH - idiopathic / familiar pulmonary arterial hypertension; CTEPH - chronic thromboembolic pulmonary hypertension; 6MWT - six minute walking test; LA - left atrium; LV - left ventricle; EF - ejection fraction; LVEDD - left ventricular enddiastolic diameter; RA - right atrium; RV - right ventricle; TAPSE - tricuspid annular plane systolic excursion; PAMP - pulmonary arterial mean pressure; RAP - right atrial pressure; PLAX - parasternal long axis view; A4C - apical four chamber view. 
Table 3. Spectrum of arrhythmia in relation to the time of its diagnosis and the diagnosis of pulmonary hypertension.

\begin{tabular}{lccccc}
\hline Diagnosis of arrhythmia & $\begin{array}{c}\text { Total number } \\
\text { of diagnosed } \\
\text { patients } \\
\mathbf{N}=\mathbf{7 9}\end{array}$ & $\begin{array}{c}\text { Prior to the } \\
\text { diagnosis } \\
\text { of } \mathbf{P H} \\
\mathbf{N = 3 1}\end{array}$ & $\begin{array}{c}\text { At the } \\
\text { diagnosis } \\
\text { of } \mathbf{P H} \\
\mathbf{N = 2 6}\end{array}$ & $\begin{array}{c}\text { After the } \\
\text { diagnosis } \\
\text { of PH } \\
\mathbf{N = 2 2}\end{array}$ & p value \\
\hline Atrial tachycardia & 16 & $8(26 \%)$ & $4(15 \%)$ & $4(18 \%)$ & - \\
Atrial fibrillation & 63 & $23(74 \%)$ & $22(85 \%)$ & $18(82 \%)$ & - \\
$-\quad$ Paroxysmal & 21 & $6(19 \%)$ & $9(35 \%)$ & $6(27 \%)$ & - \\
$-\quad$ Persistent & 21 & $11(35 \%)$ & $5(19 \%)$ & $5(23 \%)$ & - \\
$-\quad$ Permanent & 21 & $6(19 \%)$ & $8(31 \%)$ & $7(32 \%)$ & - \\
\hline
\end{tabular}

Values are expressed as $\mathrm{n}(\%) . \mathrm{PH}$ - pulmonary hypertension.

This hypothesis could be supported by the fact that in our study the parameters of age, diabetes mellitus, and arterial hypertension - frequent risk factors for left heart involvement with diastolic dysfunction - were associated with the development of arrhythmias. As suggested by Opitz (Opitz et al. 2016), these cases represent a borderline category of patients with "atypical IPAH" in whom the left heart involvement remains silent under resting conditions. Finally, in borderline PAWP cases the measurement method of PAWP may lead to an underestimation (using a digitized mean value) or overestimation (using end-expiratory values) of PAWP (Rosenkranz et al. 2016). Our data supports the hypothesis that truly elevated LA pressure could participate in the development of LA substrate and its arrhythmogenicity.

On the other hand, the high burden of paroxysmal, persistent, or permanent arrhythmia may be a cause of the LA remodelling itself (Ausma et al. 1997, Spach and Josephson 1994). Decreased atrial contraction, atrio-ventricular asynchrony, and a rapid heart rate with a reduction of diastolic filling are potential factors of left atrial remodelling. Moreover, it has been found that $\mathrm{AF}$ itself causes electrophysiological changes of the atrial myocardium which explains the progressive character of the arrhythmia (Wijffels et al. 1995, Aldhoon et al. 2010). Since in our cohort the LA diameter did not differ significantly according to the type of arrhythmia and was not dependent on the time of onset of $\mathrm{AF} / \mathrm{AT}$, the impact of pure arrhythmia's burden on atrial remodelling does not lie in simply increasing the PAWP in our study. However, aging and external stressors such as arterial hypertension or diabetes were associated with the presence of AF / AT. All these conditions are also well known factors influencing atrial electrophysiological and structural remodelling of the LA, which can be associated with the initiation of $\mathrm{AF}$ in the general population (Chimenti et al. 2010, Nguyen et al. 2009) as well as in the PH population (Medi et al. 2012). These facts are closely in accordance with our data and suggest the existence of some left-sided proarrhythmogenic substrate among patients with arrhythmia and pre-capillary $\mathrm{PH}$.

As already mentioned, the mean RAP in studied population was elevated generally. Nevertheless, there was a difference in mean RAP values between groups with low and near to elevated PAWP - patients with higher values of PAWP had also slightly higher RAP. In general, this is the most likely caused by a backward propagation of elevated PAWP through pulmonary circulation to the right ventricle and atrium. We can see that this difference in RAP between our groups did not affect the RA sizes. We speculate, that structural changes of RA are so pronounced in studied population of $\mathrm{PH}$ patients, that this small further RAP elevation simply could not affect the RA architecture.

Nearly one third of patients in the group with AF / AT were diagnosed with arrhythmia during the followup. Those patients were significantly younger than patients with a history of arrhythmia prior to the diagnosis of $\mathrm{PH}$. This can be further proof of the pro-arrhythmogenic effect of complex PH-related changes to the heart's structure, leading to arrhythmia onset in a younger age. The annual incidence of AF / AT during follow-up was around $4.5 \%$ of patients a year. However, the fluctuation of the annual incidence is considerable, being very probably caused by small number error, which is certainly more pronounced in the later years of follow-up, when the total number of patients at risk of arrhythmia is low. Nevertheless, we must keep in mind that for some patients the time of their 
diagnosis of $\mathrm{PH}$ was the real beginning of their regular follow-ups by a cardiologist. This could lead to the identification of arrhythmias (mainly paroxysmal) which had already been present for a longer time but remained silent.

\section{Limitations}

There were several limitations of our study, of which the most limiting is its retrospective and singlecentre design. Despite a meticulous and systematic followup, some arrhythmias may have been missed. Our data was mainly based on standard electrocardiograms and carefully gathered patient histories. However, due to a lack of other routinely used means of rhythm monitoring, it is likely that some self-terminating, clinically silent AF episodes may have been missed. Moreover, our hemodynamic investigation was based on a standard resting right heart catheterization, which is unable to detect cases of atypical forms of $\mathrm{PH}$ in which the PAWP may rise steeply during exertion or after a fluid challenge, unmasking the postcapillary component.

\section{Conclusion}

The overall prevalence of AF / AT in the studied group of patients with isolated pre-capillary PH (IPAH / FPAH or inoperable CTEPH) was almost $24 \%$ (79 of 333 patients). The prevalence of AF / AT increased with a growing post-capillary component. Patients with near to elevated PAWP had significantly higher occurrences of arrhythmia. Those patients were older, with more prevalent arterial hypertension and diabetes mellitus, and larger size of LA, which points to the probable coexistence of left-sided proarrhythmogenic substrate even in patients with pre-capillary PH. Nearly one third of patients were diagnosed with AF / AT later during follow-up. These patients were significantly younger compared to those patients with a history of arrhythmia prior to the diagnosis of $\mathrm{PH}$. This could be further proof of the pro-arrhythmogenic effect of complex PH-related changes in the heart's structure, leading to arrhythmia onset at a younger age.

\section{Conflict of Interest}

There is no conflict of interest.

\section{Acknowledgements}

The study was supported by Ministry of Health of the Czech Republic, grant nr. NV18-02-00027. We would like to thank Mr. Zachary H. K. Kendall, B.A. for the language editing.

\section{References}

ALDHOON B, MELENOVSKÝ V, PEICHEL P, KAUTZNER J: New insights into mechanisms of atrial fibrillation. Physiol Res. 59: 1-12, 2010. https://doi.org/10.33549/physiolres.931651

AUSMA J, WIJFFELS M, THONE F, WOUTERS L, ALLESSIE M, BORGERS M: Structural changes of atrial myocardium due to sustained atrial fibrillation in the goat. Circulation 96: 3157-3163, 1997. https://doi.org/10.1161/01.CIR.96.9.3157

BORLAUG B A, NISHIMURA R A, SORAJJA P, LAM C S, REDFIELD M M: Exercise hemodynamics enhance diagnosis of early heart failure with preserved ejection fraction. Circ Heart Fail 3: 588-595, 2010. https://doi.org/10.1161/CIRCHEARTFAILURE.109.930701

CANNILLO M, GROSSO MARRA W, GILI S, D'ASCENZO F, MORELLO M, MERCANTE L, MISTRETTA E, SALERA D, ZEMA D, BISSOLINO A, FUSARO E, MARRA S, LIBERTUCCI D, GAITA F: Supraventricular arrhythmias in patients with pulmonary arterial hypertension. Am J Cardiol 116: 1883-1889, 2015. https://doi.org/10.1016/j.amjcard.2015.09.039

CHIMENTI C, RUSSO M A, CARPI A, FRUSTACI A: Histological substrate of human atrial fibrillation. Biomed Pharmacother 64: 177-183, 2010. https://doi.org/10.1016/j.biopha.2009.09.017

CIOFFI G, DE SIMONE G, MUREDDU G, TARANTINI L, STEFENELLI C: Right atrial size and function in patients with pulmonary hypertension associated with disorders of respiratory system or hypoxemia. European Journal of Echocardiography 8: 322-331, 2007. https://doi.org/10.1016/j.euje.2006.06.006

D'ALTO M, ROMEO E, ARGIENTO P, MOTOJI Y, CORRERA A, Di MARCO G M, IACONO A M, BARRACANO R, D'ANDREA A, REA G, SARUBBI B, RUSSO M G, NAEIJE R: Clinical relevance of fluid challenge in patients evaluated for pulmonary hypertension. Chest 151: 119-126, 2017. https://doi.org/10.1016/j.chest.2016.08.1439 
FINGROVA Z, HAVRANEK S, AMBROZ D, JANSA P, LINHART A: The left atrial substrate plays a significant role in the development of complex atrial tachycardia in patients with precapillary pulmonary hypertension. BMC Cardiovasc Disord 19: 157, 2019. https://doi.org/10.1186/s12872-019-1142-Z

FINGROVA Z, AMBROZ D, JANSA P, KUCHAR J, LINDNER J, KUNSTYR J, ASCHERMANN M, LINHART A, HAVRANEK S: The prevalence and clinical outcome of supraventricular tachycardia in different etiologies of pulmonary hypertension. PLoS One 16: e0245752, 2021. https://doi.org/10.1371/journal.pone.0245752

FOLINO A F, BOBBO F, SCHIRALDI C, TONA F, ROMANO S, BUJA G, BELLOTTO F: Ventricular arrhythmias and autonomic profile in patients with primary pulmonary hypertension. Lung 181: 321-328, 2003. https://doi.org/10.1007/s00408-003-1034-x

GALIE N, TORBICKI A, BARST R, DARTEVELLE P, HAWORTH S, HIGENBOTTAM T, OLSCHEWSKI H, PEACOCK A, PIETRA G, RUBIN L J, SIMONNEAU G, PRIORI S G, GARCIA M A, BLANC J J, BUDAJ A, COWIE M, DEAN V, DECKERS J, BURGOS E F, LEKAKIS J, LINDAHL B, MAZZOTTA G, MCGREGOR K, MORAIS J, OTO A, SMISETH O A, BARBERA J A, GIBBS S, HOEPER M, HUMBERT M, NAEIJE R, PEPKE-ZABA J, TASK F: Guidelines on diagnosis and treatment of pulmonary arterial hypertension. The Task Force on Diagnosis and Treatment of Pulmonary Arterial Hypertension of the European Society of Cardiology. Eur Heart J 25: 2243-2278, 2004.

GALIE N, HOEPER M M, HUMBERT M, TORBICKI A, VACHIERY J L, BARBERA J A, BEGHETTI M, CORRIS P, GAINE S, GIBBS J S, GOMEZ-SANCHEZ M A, JONDEAU G, KLEPETKO W, OPITZ C, PEACOCK A, RUBIN L, ZELLWEGER M, SIMONNEAU G, GUIDELINES E S C C F P: Guidelines for the diagnosis and treatment of pulmonary hypertension: the Task Force for the Diagnosis and Treatment of Pulmonary Hypertension of the European Society of Cardiology (ESC) and the European Respiratory Society (ERS), endorsed by the International Society of Heart and Lung Transplantation (ISHLT). Eur Heart J 30: 2493-2537, 2009.

GALIE N, HUMBERT M, VACHIERY J L, GIBBS S, LANG I, TORBICKI A, SIMONNEAU G, PEACOCK A, VONK NOORDEGRAAF A, BEGHETTI M, GHOFRANI A, GOMEZ SANCHEZ M A, HANSMANN G, KLEPETKO W, LANCELLOTTI P, MATUCCI M, MCDONAGH T, PIERARD L A, TRINDADE P T, ZOMPATORI M, HOEPER M, ABOYANS V, VAZ CARNEIRO A, ACHENBACH S, AGEWALL S, ALLANORE Y, ASTEGGIANO R, PAOLO BADANO L, ALBERT BARBERA J, BOUVAIST H, BUENO H, BYRNE R A, CARERJ S, CASTRO G, EROL C, FALK V, FUNCK-BRENTANO C, GORENFLO M, GRANTON J, IUNG B, KIELY D G, KIRCHHOF P, KJELLSTROM B, LANDMESSER U, LEKAKIS J, LIONIS C, LIP G Y, ORFANOS S E, PARK M H, PIEPOLI M F, PONIKOWSKI P, REVEL M P, RIGAU D, ROSENKRANZ S, VOLLER H, LUIS ZAMORANO J: 2015 ESC/ERS Guidelines for the diagnosis and treatment of pulmonary hypertension: The Joint Task Force for the Diagnosis and Treatment of Pulmonary Hypertension of the European Society of Cardiology (ESC) and the European Respiratory Society (ERS): Endorsed by: Association for European Paediatric and Congenital Cardiology (AEPC), International Society for Heart and Lung Transplantation (ISHLT). Eur Heart J 37: 67-119, 2016. https://doi.org/10.1093/eurheartj/ehv317

MEDI C, KALMAN J M, LING L H, TEH A W, LEE G, LEE G, SPENCE S J, KAYE D M, KISTLER P M: Atrial Electrical and Structural Remodeling Associated with Longstanding Pulmonary Hypertension and Right Ventricular Hypertrophy in Humans. J Cardiovasc Electr 23: 614-620, 2012. https://doi.org/10.1111/j.1540$\underline{8167.2011 .02255 . \mathrm{X}}$

NGUYEN B L, FISHBEIN M C, CHEN L S, CHEN P S, MASROOR S: Histopathological substrate for chronic atrial fibrillation in humans. Heart Rhythm 6: 454-460, 2009. https://doi.org/10.1016/j.hrthm.2009.01.010

OLSSON K M, NICKEL N P, TONGERS J, HOEPER M M: Atrial flutter and fibrillation in patients with pulmonary hypertension. Int J Cardiol 167: 2300-2305, 2013. https://doi.org/10.1016/j.ijcard.2012.06.024

OPITZ C F, HOEPER M M, GIBBS J S, KAEMMERER H, PEPKE-ZABA J, COGHLAN J G, SCELSI L, D'ALTO M, OLSSON K M, ULRICH S, SCHOLTZ W, SCHULZ U, GRUNIG E, VIZZA C D, STAEHLER G, BRUCH L, HUSCHER D, PITTROW D, ROSENKRANZ S: Pre-Capillary, Combined, and Post-Capillary Pulmonary Hypertension: A Pathophysiological Continuum. J Am Coll Cardiol 68: 368-378, 2016. https://doi.org/10.1016/j.jacc.2016.05.047 
PIETRA G G, CAPRON F, STEWART S, LEONE O, HUMBERT M, ROBBINS I M, REID L M, TUDER R M: Pathologic assessment of vasculopathies in pulmonary hypertension. J Am Coll Cardiol 43: 25S-32S, 2004. https://doi.org/10.1016/j.jacc.2004.02.033

ROSENKRANZ S, GIBBS J S, WACHTER R, DE MARCO T, VONK-NOORDEGRAAF A, VACHIERY J L: Left ventricular heart failure and pulmonary hypertension. Eur Heart J 37: 942-954, 2016. https://doi.org/10.1093/eurheartj/ehv512

ROTTLAENDER D, MOTLOCH L J, SCHMIDT D, REDA S, LARBIG R, WOLNY M, DUMITRESCU D, ROSENKRANZ S, ERDMANN E, HOPPE U C: Clinical impact of atrial fibrillation in patients with pulmonary hypertension. PLoS One 7: e33902, 2012. https://doi.org/10.1371/journal.pone.0033902

SCHRIER R W, BANSAL S: Pulmonary hypertension, right ventricular failure, and kidney: different from left ventricular failure? Clin J Am Soc Nephrol 3: 1232-1237, 2008. https://doi.org/10.2215/CJN.01960408

SIMONNEAU G, GALIE N, RUBIN L J, LANGLEBEN D, SEEGER W, DOMENIGHETTI G, GIBBS S, LEBREC D, SPEICH R, BEGHETTI M, RICH S, FISHMAN A: Clinical classification of pulmonary hypertension. J Am Coll Cardiol 43: 5S-12S, 2004. https://doi.org/10.1016/j.jacc.2004.02.037

SMITH B, GENUARDI M V, KOCZO A, ZOU R H, THOMA F W, HANDEN A, CRAIG E, HOGAN C M, GIRARD T, ALTHOUSE A D, CHAN S Y: Atrial arrhythmias are associated with increased mortality in pulmonary arterial hypertension. Pulm Circ 8: 2045894018790316, 2018. https://doi.org/10.1177/2045894018790316

SPACH M S, JOSEPHSON M E: Initiating reentry: the role of nonuniform anisotropy in small circuits. J Cardiovasc Electrophysiol 5: 182-209, 1994. https://doi.org/10.1111/j.1540-8167.1994.tb01157.x

TONGERS J, SCHWERDTFEGER B, KLEIN G, KEMPF T, SCHAEFER A, KNAPP J M, NIEHAUS M, KORTE T, HOEPER M M: Incidence and clinical relevance of supraventricular tachyarrhythmias in pulmonary hypertension. Am Heart J 153: 127-132, 2007. https://doi.org/10.1016/j.ahj.2006.09.008

WEN L, SUN M L, AN P, JIANG X, SUN K, ZHENG L, LIU Q Q, WANG L, ZHAO Q H, HE J, JING Z C: Frequency of Supraventricular Arrhythmias in Patients With Idiopathic Pulmonary Arterial Hypertension. Am J Cardiol 114: 1420-1425, 2014. https://doi.org/10.1016/j.amjcard.2014.07.079

WIJFFELS M C, KIRCHHOF C J, DORLAND R, ALLESSIE M A: Atrial fibrillation begets atrial fibrillation. A study in awake chronically instrumented goats. Circulation 92: 1954-1968, 1995. https://doi.org/10.1161/01.CIR.92.7.1954 